\title{
DEVELOPING SPORT INTEGRITY COMPETENCES IN PRE-SERVICE COACHES
}

\section{Monica STĂNESCU ${ }^{1 *}$, Vasilica GRIGORE ${ }^{1}$, Marius STOICESCU ${ }^{1}$, Pompiliu Nicolae CONSTANTIN ${ }^{1}$}

\author{
${ }^{1}$ National University of Physical Education and Sport, Faculty of Physical Education and Sport, Bucharest, Romania \\ *Corresponding author: monica_iulia@yahoo.com
}

DOI: 10.35189/iphm.icpesk.2019.44

\begin{abstract}
The aim of this paper is to reveal the level of competences of pre-service coaches in terms of sport integrity, a level acquired through an academic course developed within the Erasmus Plus Sport project called "Development of a Course to Teach Coaches Sport Integrity". This approach consisted in the application of a questionnaire, both before and after the course, on the topic of integrity in sport. Twenty students responded to the proposed questionnaire. In addition, other 78 students who did not participate in the course activities were surveyed as well. The study results showed significant increases in the level of specialised knowledge and the skills of identifying and reporting irregularities in sport, but also the learners' susceptibility to act effectively when faced with various challenging situations. The obtained results provide important feedback in the attempt to identify the strengths and weaknesses of the course. It also provides an instrument to improve both its content and the way it is distributed. The reality in the contemporary sport, coupled with the conclusions reached in our analysis, highlight the need for the academic implementation of the concept of integrity in sport in order to develop specific skills useful to generations of future coaches.
\end{abstract}

Keywords: ethics, clean sport, students.

\section{Introduction}

Ethics has become a crucial topic in recent years, especially due to some punctual or larger crises generated by violations of ethical principles. This context has led to a general phenomenon named "calls for the teaching of ethics", which is regularly addressed in the media and targets various fields such as technology, politics, medicine, sport and economy. Ethical deficiencies are reported everywhere. Therefore, the issue of ethics and integrity is a priority for the institutions involved in training specialists in different fields such as those mentioned above.

Since the 1990s, several researchers have studied the characteristics of designing content that will contribute to the formation of professional ethics. Following a study in the nursing area, Duckett and Ryden (1994) have concluded that the ethical knowledge introduced in the initial training curriculum influences moral thinking in the professional activity. Moreover, it has been found that the level of moral thinking can be used as a predictor for the professional performance of nursing students. Applying the theory of the four elements of ethics, Duckett and Ryden (1994) propose as a structure of any ethics course a series of theoretical knowledge (moral theory, etc.) that allows building the ability to make ethical decisions and increasing the ability to communicate aspects of professional ethics; developing critical thinking that enables students to analyse the elements that underlie a decision; raising awareness of one's own system of values and beliefs and training for the ability to recognize when they may conflict with the responsibility or position required by ethical behaviour; developing the ability to apply an ethical decision once it has been made.

Narvaez (2010) argues that moral expertise can be cultivated in organizations using the integrative ethical education model. Also, the literature describes a number of useful methods for moral education, such as case study, role play, perception analysis, and supports the accessibility of including it in the coach training curriculum. One can speak of a genuine pedagogy of morals, which, introduced in the training curriculum of coaches, generates long-term moral decisions and behaviours (Cruz-Cruz, Curbelo, \& Frey, 2010). These issues were summarised by Wishloff (2005) in the phrase: "Our theorizing must start with human beings" (p. 80), suggesting that interaction and personal experiences make the theory applicable in the field of ethics.

Hughes and Gallant (2016) argue that the training of specialists from the perspective of ethical decisionmaking process is required as an absolutely necessary measure which, once adopted, illustrates how universities assume responsibility in this regard. These institutions offer the first models of professional integrity. As far as the design of the ethics courses is concerned, the question was whether to devise a stand-alone course or to include certain information within other academic subjects. Any of the two variants allows students in the initial years of training to face different situations of professional ethics, whose resolution is subsequently applied in their professional activities. Moreover, such programs offer students the opportunity to assimilate not only theoretical 
knowledge, but also enable them to apply this knowledge, to debate it and thus to develop their skills and specific ethical attitudes. (Hughes \& Gallant, 2016)

\section{Coaching ethics}

Sport is an area in which there are numerous rules and regulations that have led over time to building codes of ethics, whose role is to standardise the behaviour of coaches, athletes and other participants in the sporting phenomenon. For example, the British Institute of Sport Coaches has established a code of ethics that covers several aspects such as integrity, confidentiality, safety, abuse of power, etc. (Mackenzie, 2001). The U.S. National Youth Sports Coaches Association (2015) asks coaches to sign a code of ethics and thus adhere to the creation of a safe environment for athletes by promoting the state of emotional and social well-being, clean sport and accepting sports regulation.

These examples can also be found in other countries or in each sports organization to regulate the behaviour of coaches and their professional relationships through the operating regulations or the deontological code.

Starting from the premise that coaches play an essential role in the moral education of athletes and considering that professional duties imply a moral rigor that resides in the nature of the sport (Hardman, Jones, \& Jones, 2010), strengthening the coach integrity and transferring it to the practical activity is an objective of the training programmes for sports specialists. Therefore, the system of personal beliefs, morals and beliefs that influence their decisions and behaviour must be solid and correctly oriented in relation to social values in general and to sport in particular. In order to achieve standards of sporting excellence, the coach must consider the athletes' motor skills, as well as their ethical and moral qualities, such as "perseverance, patience, magnanimity in victory and grace in defeat" (Hardman et al., 2010, p. 347).

Studies have shown that sport, as a complex field, with a particular dynamic of relationships and situations that coaches have to deal with, implies from them a series of skills that aim decision making, including decisions of ethical nature. While some researchers argue that taking responsibility is an ability of coaches influenced by experience (Cushion, Armour, \& Jones, 2003), others believe that the ethics of coaches can be the result of the educational process in which they participate (Bredemeier \& Shields, 1986). This is the reason for which ethics was introduced in the initial curriculum of vocational training and in other fields (medicine, psychology, etc.).

\section{The training of coaches in Romania from the perspective of clean sport}

Regarding the training of coaches from the perspective of clean sport, this is provided by different qualified institutions, among which we list the specific colleges, the National Anti-Doping Agency (ANAD) and the Romanian Olympic and Sports Committee (COSR). Each institution acts on its own, approaching in different ways the punctual, local or systemic problems of Romanian sport. In addition, each institution has its own standards, depending on the place occupied in the sports landscape. The specific colleges offer a general approach in which nothing focuses on performance sport, while the COSR has an even narrower segment, targeting only the Olympic performance sports. Therefore, the target audience is different.

University curriculum provides a course on Ethics and Deontology in Physical Education and Sport, usually included in the curriculum of Bachelor's or Master's Programmes. The main topics are anti-doping education, list of prohibited substances and legislation against doping behaviour. In addition to these topics, the course covers, in general, other content specific to ethics and integrity, such as harassment, match fixing, good governance in sport organizations and abuses in sport.

Whether it was linked to politics, sport or medicine, it has often been stated that "ethics is boring" (Bertolami, 2004). However, the courses must overcome this weakness, which is frequently mentioned in ethics studies.

A model of good practice in the field of moral education of coaches is represented by the Erasmus Plus Sport project "Development of a Course to Teach Coaches Sport Integrity" (2017-3344/ 001-001), coordinated by the Aristotle University of Thessaloniki (Greece) and also in Romania, by the National University of Physical Education and Sport of Bucharest (UNEFS), as a partner. The project aims to raise public but especially coach awareness of the importance of promoting ethical conduct based on the integration of moral principles in sport.

The purpose of the course designed within the above-mentioned project was to develop the skills of the participants in the following directions:

- Ability to understand the complex form of certain types of corruption in sport, such as doping;

- Ability to critically evaluate information and to draw argument-based clear conclusions on the intended action to combat corruption in sport;

- Ability to identify the most appropriate ways to maintain good governance and integrity in sport. 
The original way of designing and implementing the course of Ethics and Integrity in Sport intended for students, future specialists in different branches of sport (long-version course) and coaches (short-version course) represents the differential note of novelty and added value brought by the project. The interactive teaching methods supported by bibliographic resources uploaded on the e-learning platform of the university, as well as invitations from the ANAD to debate doping-related themes, were some of the strong points of the course.

In this context, the purpose of the paper is to highlight the impact of the ethics course developed within the Erasmus Plus Sport project "Development of a Course to Teach Coaches Sport Integrity" on students from the Physical and sport education and Sport and motor performance programmes offered by the UNEFS Bucharest.

The content of the course was approved by the project consortium, and the paper presents the efficiency of the programme for the target group. There were no risks for the group members participating in the course.

Our study relies on two hypotheses:

1. The practice of performance sports creates favourable conditions for the formation of competences regarding the defence of ethics and integrity in sport for athlete students, as compared to non-athlete students.

2. The ethics and integrity course conducted within the aforementioned project induces significant changes in the students' competence system, given that it is run according to the variables of the didactic design (content, methods and means, number of hours and informational resources).

\section{Material and Methods}

To measure the impact of this course on students, qualitative methods were used, which allowed obtaining accurate data by direct application, under the protection of anonymity, to encourage honest responses. Such an approach allows the construction of a context of comparative analysis (Duşa, 2014), by correlating the statistical data with the observations made by the teachers throughout the course. The latter aspect is a qualitative method (Patton, 2002) and provides additional information on how the course was conducted, capturing the behavioural instances of the students. No matter how complex the modern quantitative methods are, they are not sufficient to explain certain social behaviours. And ethical issues fall into this category.

To assess the students' level of competence, an original questionnaire was applied before and after the course. It contained 24 items referring to knowledge about the topics of sports ethics, skills and action skills for the protection of sports ethics and moral values. At the same time, the opinions of students regarding the need to participate in a course of Ethics and integrity in sport were also evaluated. The evaluation was done using a 5-step Likert Scale, where 1 means "strongly disagree", 2 - "disagree", 3 - "neutral", 4 - "agree", and 5 - "strongly agree".

The questionnaire applied at the end of the course also evaluated the content, methods and means applied (9 items), as well as the way the course was conducted. The evaluation was performed using a 7-step Likert Scale.

The internal consistency of the questionnaire was calculated with Cronbach's Alpha test from the SPSS 24.00, whose value was 0.889 (above the critical threshold of 0.70 , which needed to be overcome for the questionnaire to be considered reliable).

For the result analysis, the coefficient of variation (Cv) and the significance of the differences between the initial and final means (t-Test), calculated with the SPSS 24.0, were used.

The questionnaire, as a working tool, was coupled with the scientific observation of the students who attended the course. This qualitative method, recommended when there is a limited number of subjects, contributes to the in-depth study of the phenomenon.

\section{Target group}

To determine the level of initial competence among students, 78 students from the Faculty of Physical Education and Sport were questioned. There were 43 students practicing various branches of sport and 25 amateur athletes.

Subsequently, according to the project methodology (that mentioned the free consent of the student to be involved in), a group of 20 students was formed to participate in the course of Ethics and integrity in sport. None of the students had taken similar courses before, and this was the only criteria for admission in the target group. The education level of the group members is shown in Figures 1 and 2. No demographic criteria were applied.

All students signed an informed consent to participate in the course and a General Data Protection Regulation Consent, according to the Erasmus Plus Sport project guide. During the project, all partners applied a set of measures to maintain privacy and confidentiality of data. 


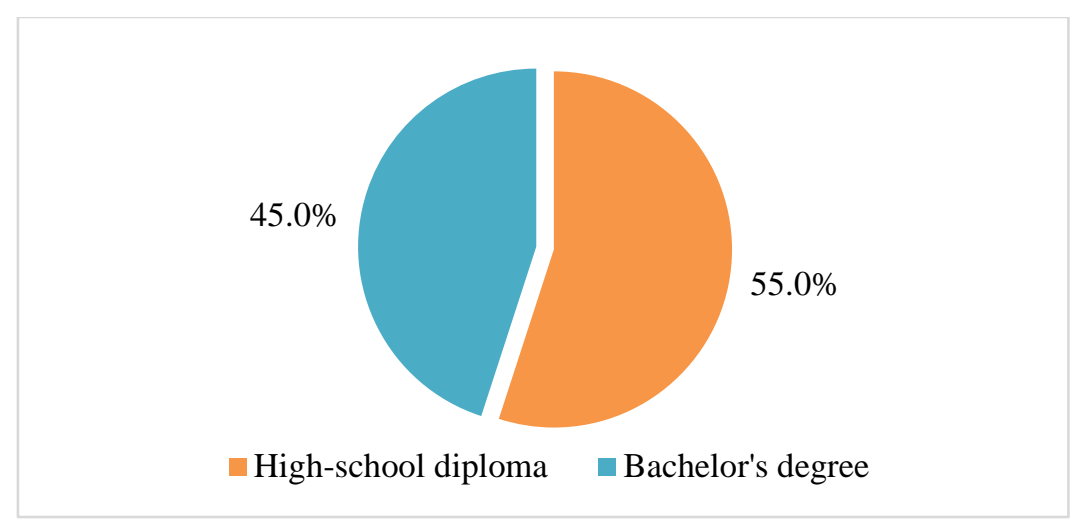

Figure 1. Target group - Education level

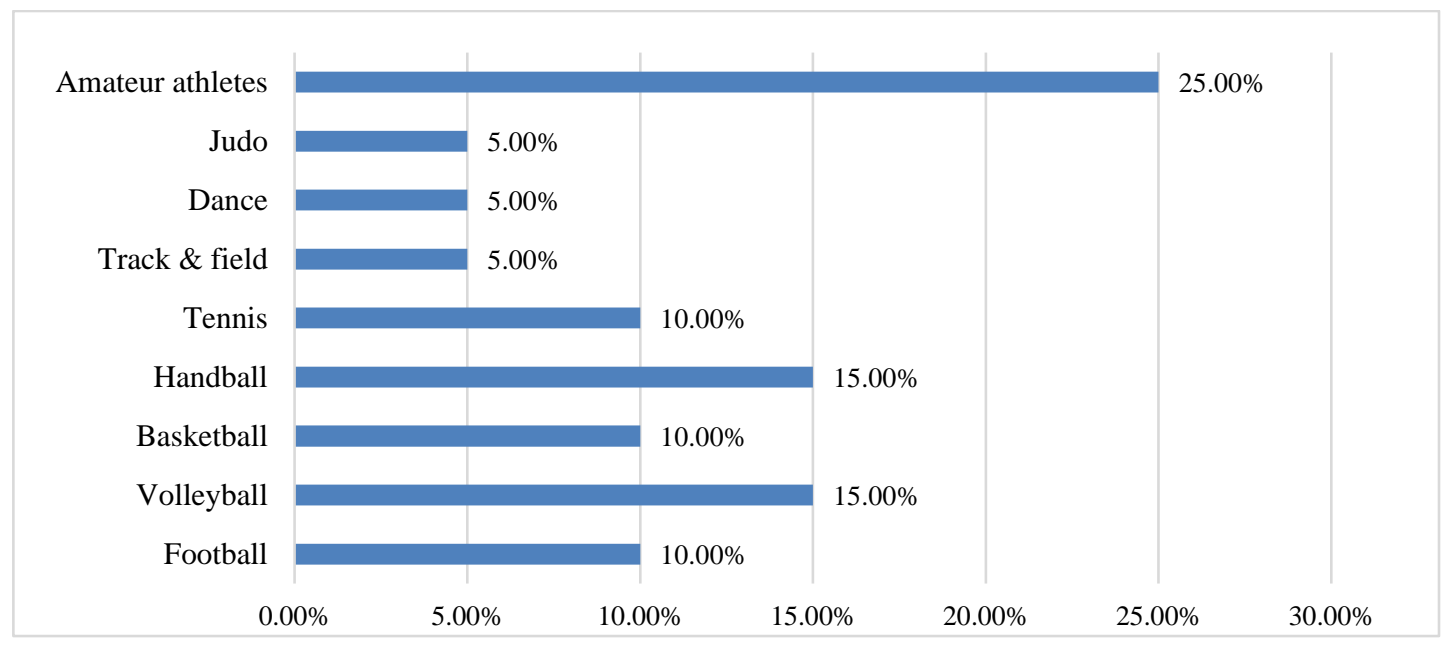

Figure 2. Target group - Sports field

\section{Organization of the course}

The course was designed for a total of 28 hours (lectures and practical activities, interactive) and was structured on the following topics: good governance in sport, corruption in sport, doping, match fixing and whistleblowing. For the evaluation, participants in the course prepared an essay of 1500 words (from the thematic course) that they presented for 10 minutes with the help of a PowerPoint presentation.

\section{Results}

The analysis of responses to the questionnaire was carried out for each of the three components of the competences concerned (knowledge, skills, attitudes) to highlight the opinions on the Ethics and integrity course.

1. The initial evaluation of the 78 students found that those who had not practiced performance sports had a lower level of knowledge regarding ethics and integrity in sport (Figure 3). The differences between the two groups are not statistically significant at $\mathrm{p}=0.05$. 
International Proceedings of Human Motricity/ ICPESK 2019

Supplementary Issue of Discobolul - Physical Education, Sport and Kinetotherapy Journal, 2019

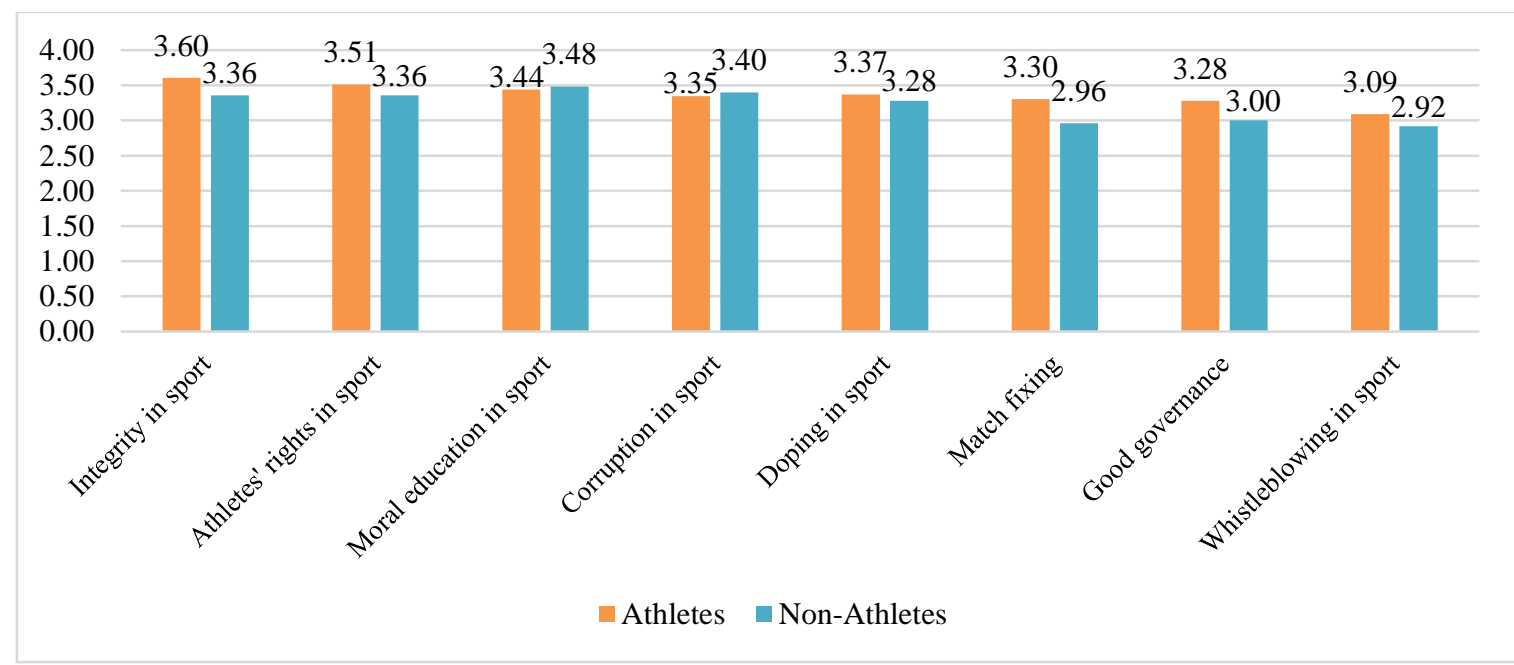

Figure 3. Comparative level of knowledge between athletes and non-athletes

Although they assess themselves with a lower level of knowledge in this area, non-athletes believe that, if they were to face ethical violations, they would better know how to act compared to athletes (Figure 4). The application of Student's t-Test has revealed that the differences between the two groups are not significant at $\mathrm{p}=0.05$.

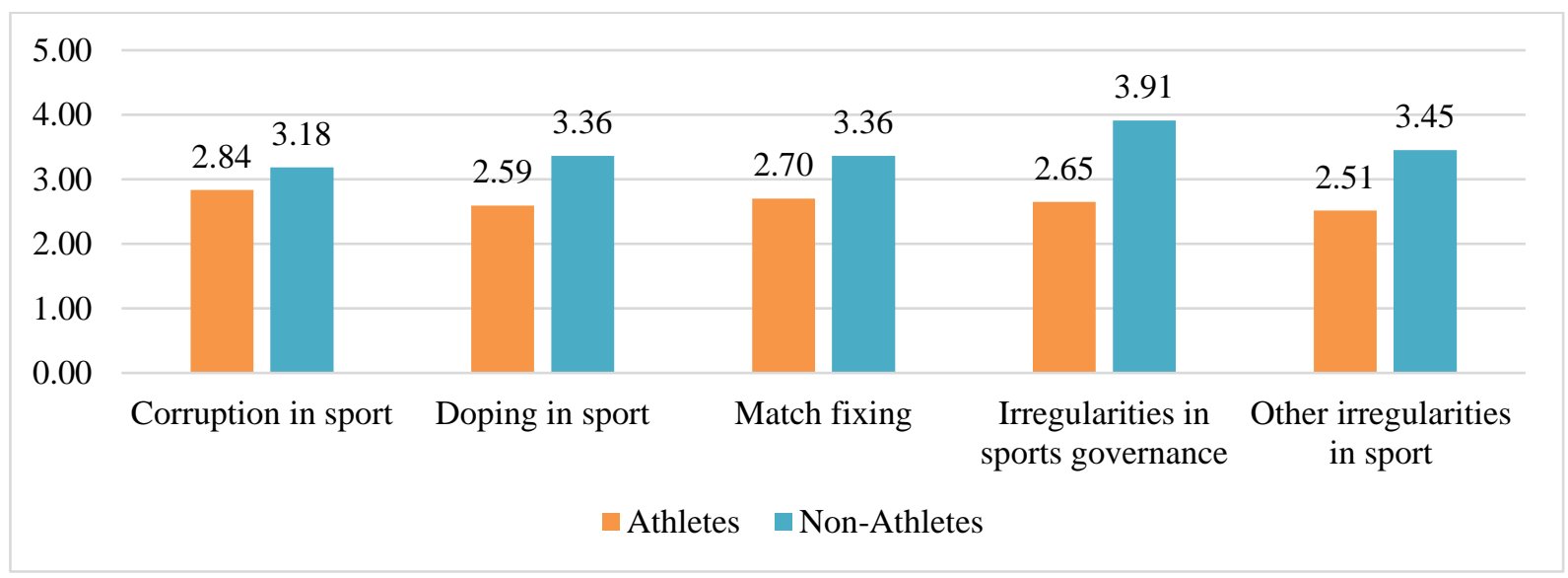

Figure 4. Knowing the procedures to act against irregularities in sport

In a similar way, non-athletes are more likely to act in favour of clean sport than those who have practiced performance sports (Figure 5). Even in this situation, the difference between groups is not significant at $\mathrm{p}=0.05$.

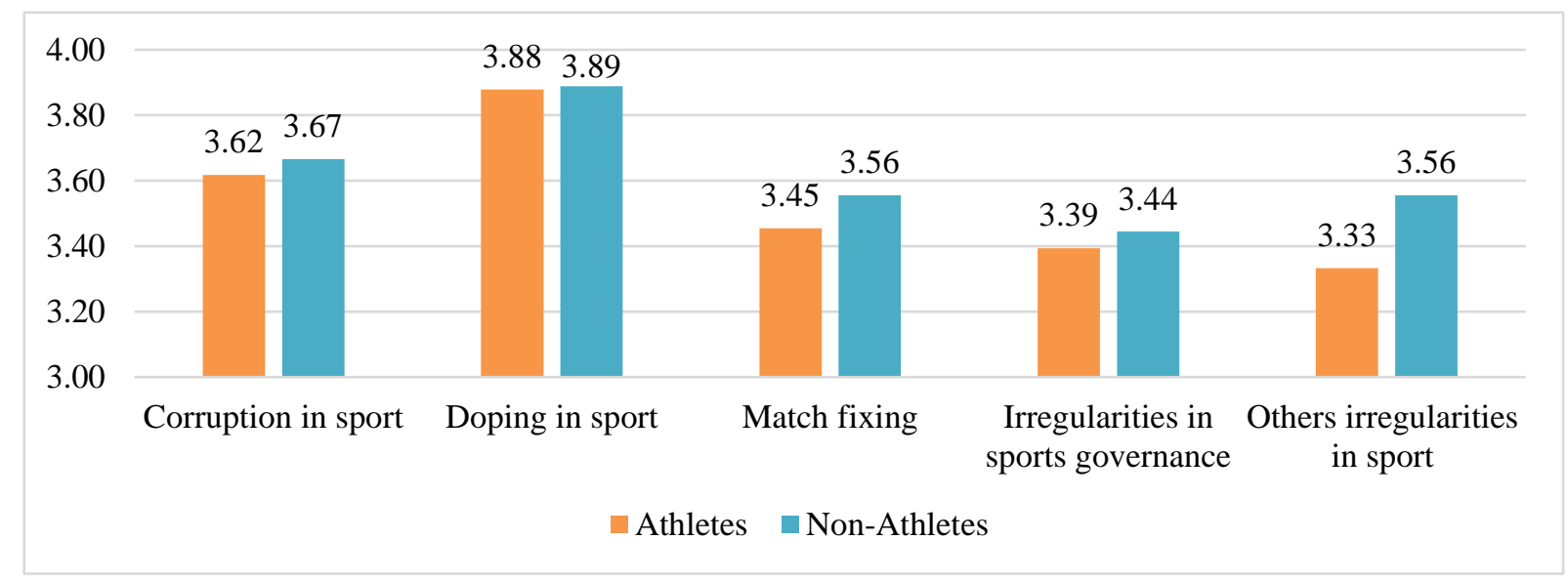

Figure 5. Willingness to take action against sport irregularities 
Although the differences between the two groups are not significant, the fact that athletes and non-athletes have a similar level of knowledge allows us to state that practicing performance sport does not foster additional educational conditions for moral development and knowledge assimilation in this area, and that students, even non-athletes, can use additional sources of information and skill development in the field of ethics and integrity. Moreover, we believe that the openness displayed by non-athletes to act in favour of clean sport is also the consequence of a weaker knowledge of the sporting phenomenon, and their availability is the consequence of a good level of moral development.

2. In the case of the group of students participating in the course, the status of athlete or non-athlete was no longer considered, given the insignificant differences between groups. Regarding the knowledge of ethics and integrity in sport before starting the course, the level of the participants was between 2.32 and 3.11 (on a 5-step Likert Scale) (Figure 6). This average level was self-rated for all topics covered by the course. Participation in the theoretical and practical activities brings a significant increase in the level of knowledge $(t=17.9, p=0.05)$, the highest level being recorded for the topic of doping (4.60). On the other hand, Figure 7 shows an improvement in homogeneity concerning the level of knowledge, which is expressed by decreased values of the coefficient of variance. Although the group still shows average homogeneity of the knowledge level, some progress has been made, which proves the assimilation of theoretical knowledge by most of the course participants.

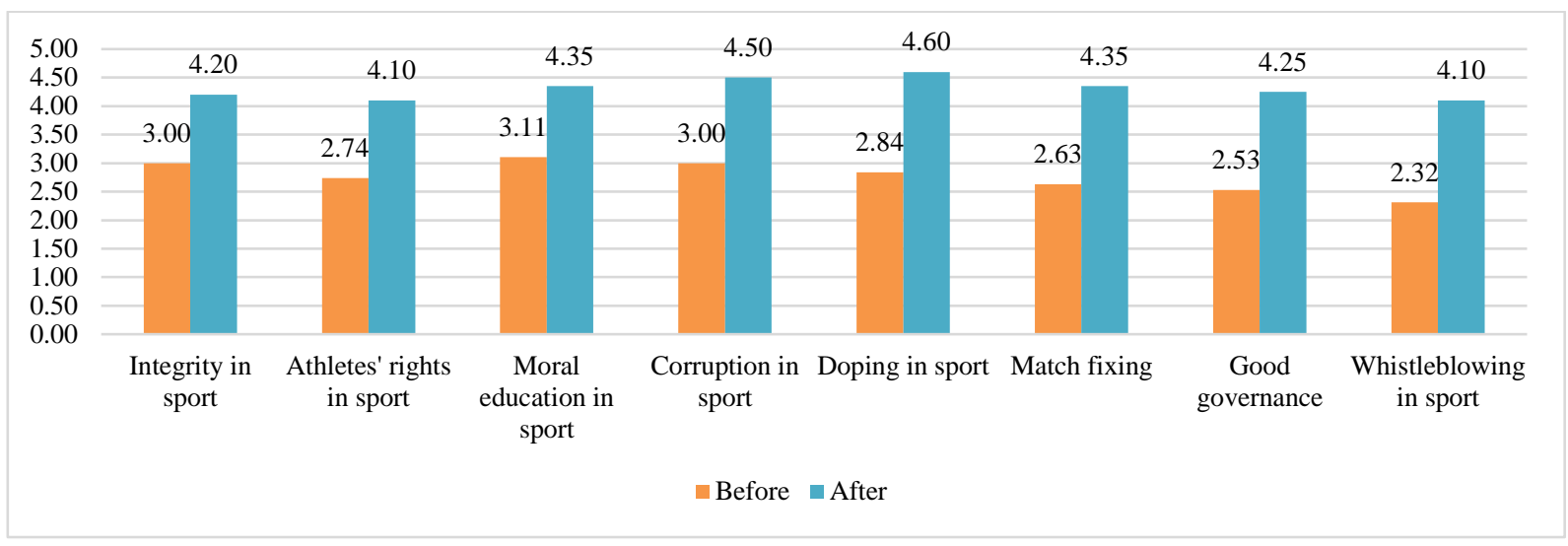

Figure 6. Level of students' knowledge (mean)

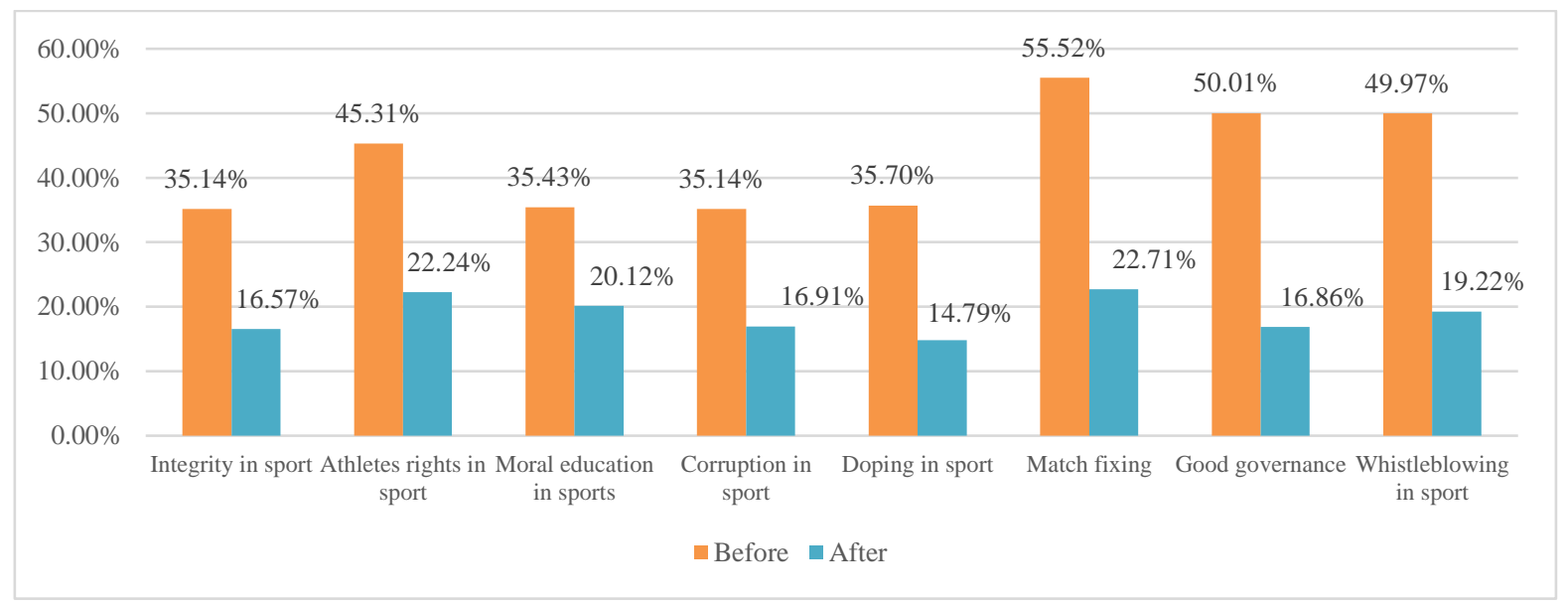

Figure 7. Level of students' knowledge (coefficient of variance)

In terms of the skills acquired during the course, namely the ability of the students to act effectively against the violation of ethics and integrity in sport, we found that students have learned the necessary steps they have to take in order to report irregularities (Figure 8). From a low initial level of knowledge of the mechanisms that they can use for the defence of clean sport (between 1.91 and 2.64 on the Likert Scale), at the end of the course, the students self-evaluate their skill level at values between 4.20 and 4.40 (on a 5-step Likert Scale). The difference between the average of the initial and final results is significant at $\mathrm{p}=0.05(\mathrm{t}=12.95)$. 
International Proceedings of Human Motricity/ ICPESK 2019

Supplementary Issue of Discobolul - Physical Education, Sport and Kinetotherapy Journal, 2019

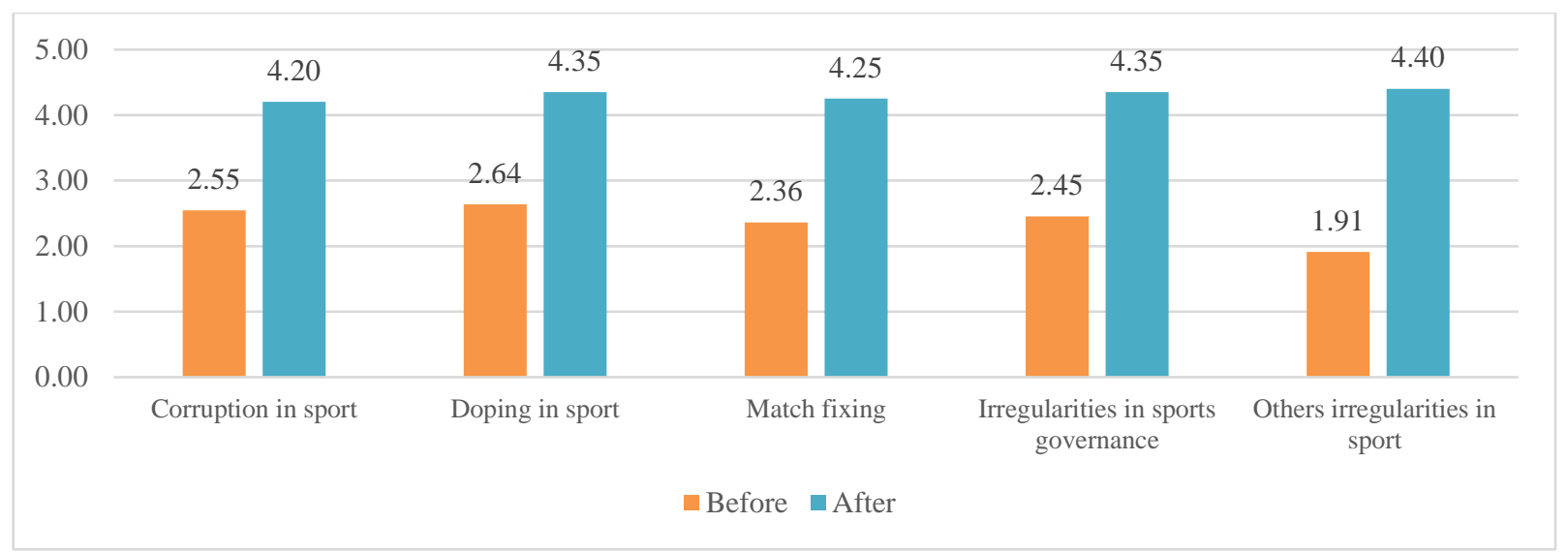

Figure 8. Knowing how to defend (mean)

As in the case of knowledge, we have found that there is an improvement in homogeneity concerning the selfesteem level in connection with the actions taken against sport irregularities. From a lack of homogeneity, there is a shift towards an area of moderate homogeneity (Figure 9), which demonstrates the progress of most students. During the debates planned for the students to learn about the sport environment in which they operate, they claimed that they perceived a low level of concern for ethical issues around them. They cited causes such as difficult access to regulations, a quasi-general lack of interest manifested by sport clubs and federations in promoting ethics and morals, the fear of athletes and coaches to address the issue of ethics and thus promote negative examples in the media. The students believe that the lack of action against sport irregularities can be a consequence of these aspects.

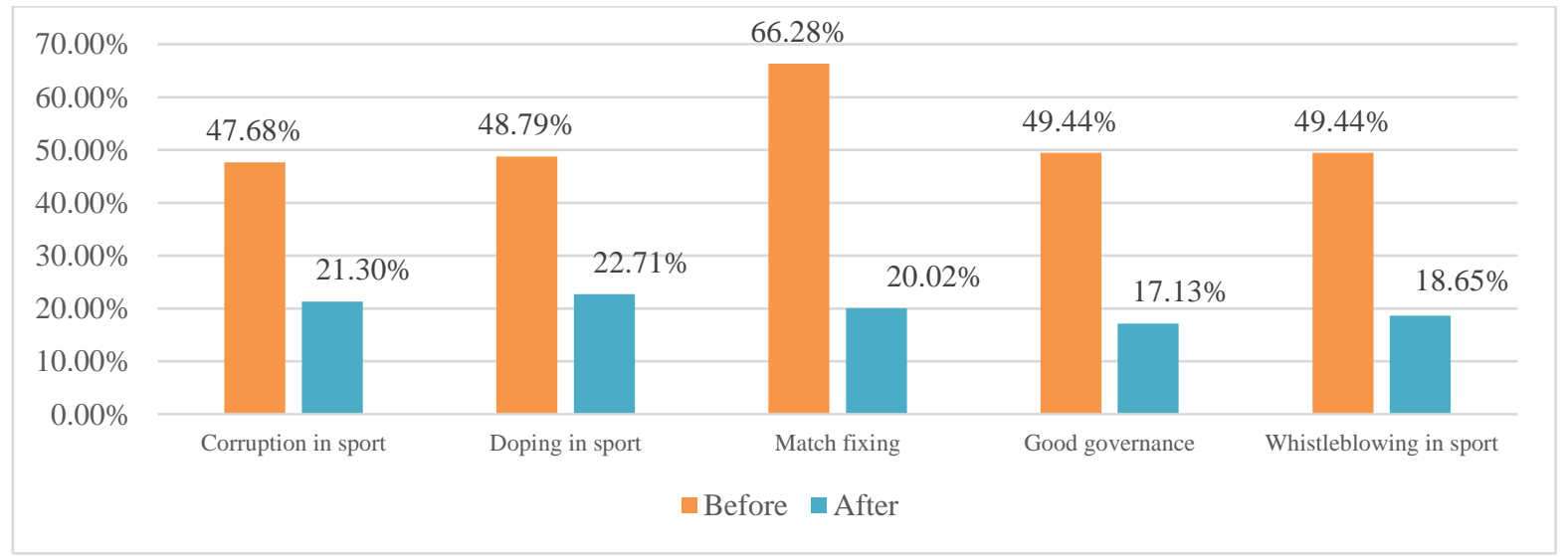

Figure 9. Knowing how to defend (coefficient of variation)

At the beginning of the course, the level of effective involvement of the students in actions to promote clean sport was ranging between 2.77 and 3.27 (Figure 10). We notice that, at the end of the course, their predisposition to engage in concrete actions to report irregularities in sport is significantly higher $(\mathrm{t}=11.98, \mathrm{p}=0.05)$, and their self-esteem level ranges from 4.25 to 4.50 . This aspect has also been tested through role-play. The students were invited to take on the role of an athlete or coach in an ethical dilemma situation. Then they were asked to explain the steps they would take. At the same time, the students were invited to retrospectively analyse the situation and to say how they would have solved the same case before attending the course. Generally, the students noticed favourable changes in their approach and observed a multiplication of the questions that they asked themselves in the moments of personal introspection related to ethics. However, there were also reservations regarding the fact that, in a similar real situation, the students could complete the steps suggested during the course. 
International Proceedings of Human Motricity/ ICPESK 2019

Supplementary Issue of Discobolul - Physical Education, Sport and Kinetotherapy Journal, 2019

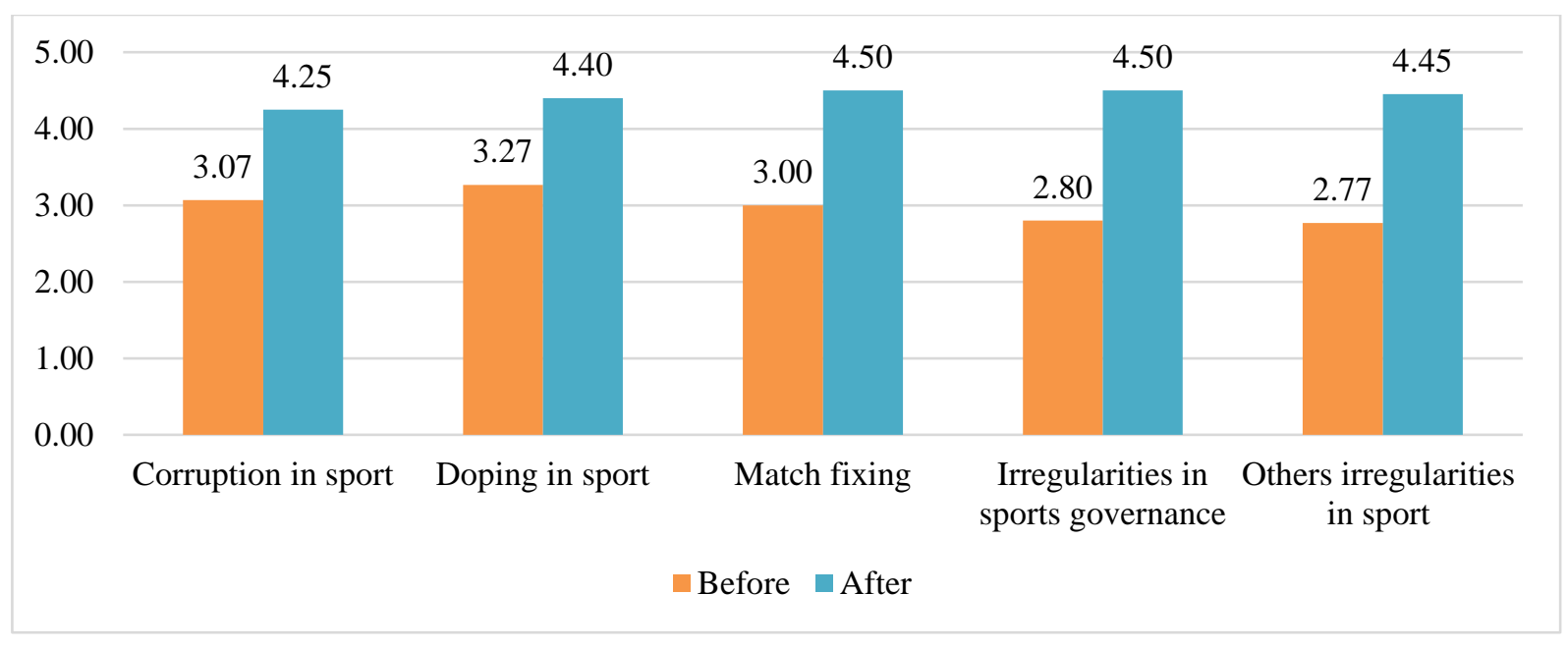

Figure 10. Predisposition to act for defending the clean sport (mean)

Regarding the students, the level of the group homogeneity is improved, and the values of the coefficient of variance reached average values for three of the five content categories (Figure 8).

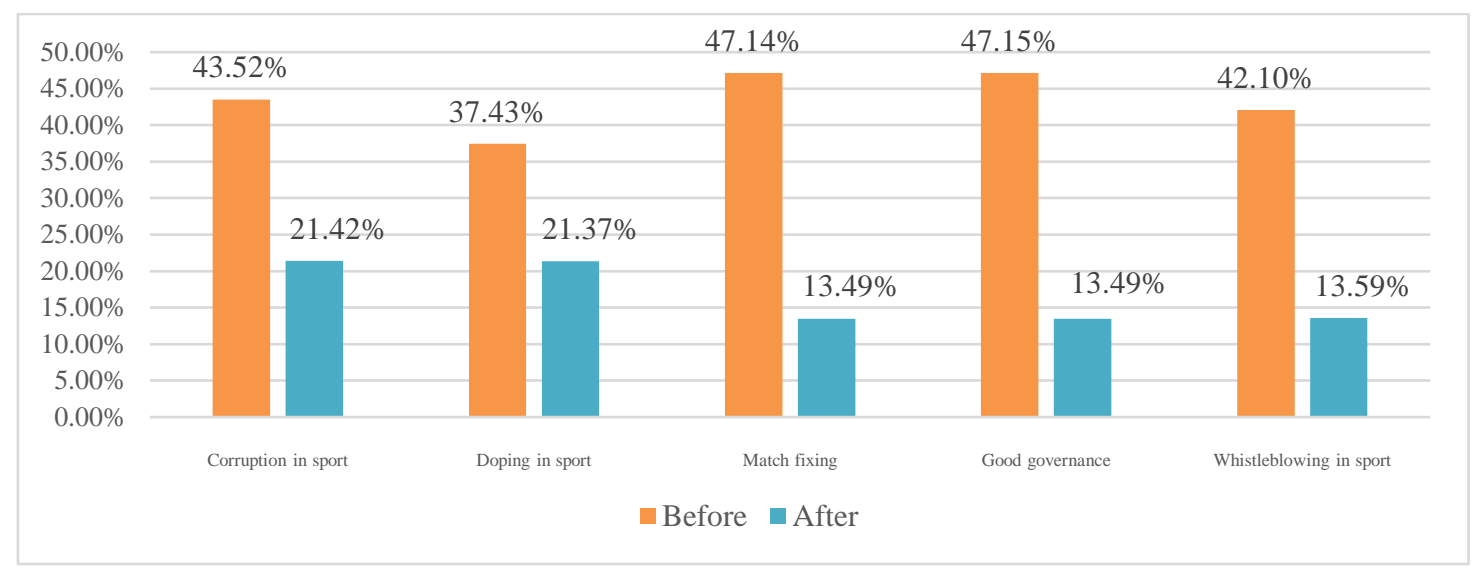

Figure 11. Predisposition to act for defending clean sport (coefficient of variation)

3. The questionnaire aims to find out how the students perceive the educational material. In this sense, the general impression (summarised in the graph below) was favourable, the students appreciating the approach proposed by the course and educational support. The usefulness of the information provided (with a coefficient of 4.75) and how they were taught (4.75) were appreciated most by the students. (Figures 12, 13 and 14)

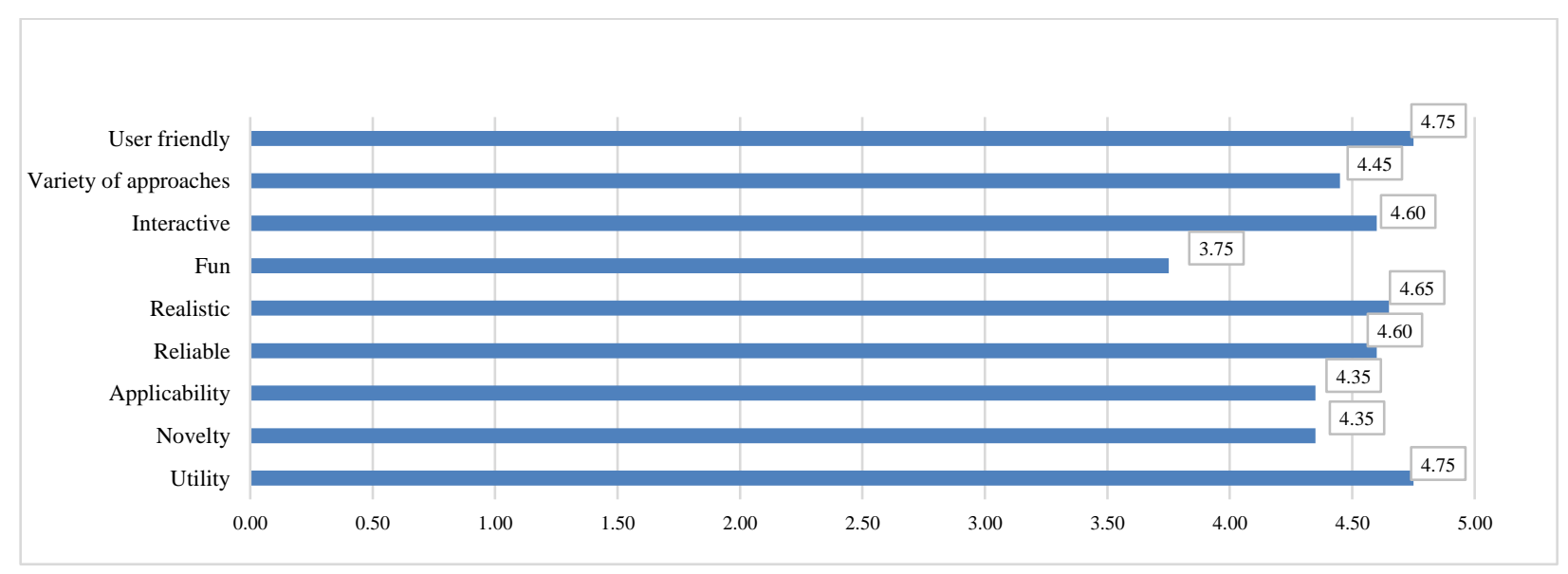

Figure 12. Evaluation of the educational material (mean) 
Another relevant aspect is the interactivity of the material, which consists of many case studies and exercises, thus allowing the students to get involved in debates, prompting them to analyse and approach different cases from different sports. This approach has allowed the creation of a more realistic framework with verified information, the sources of which have been constantly mentioned, precisely to provide a concrete and effective character for this course.

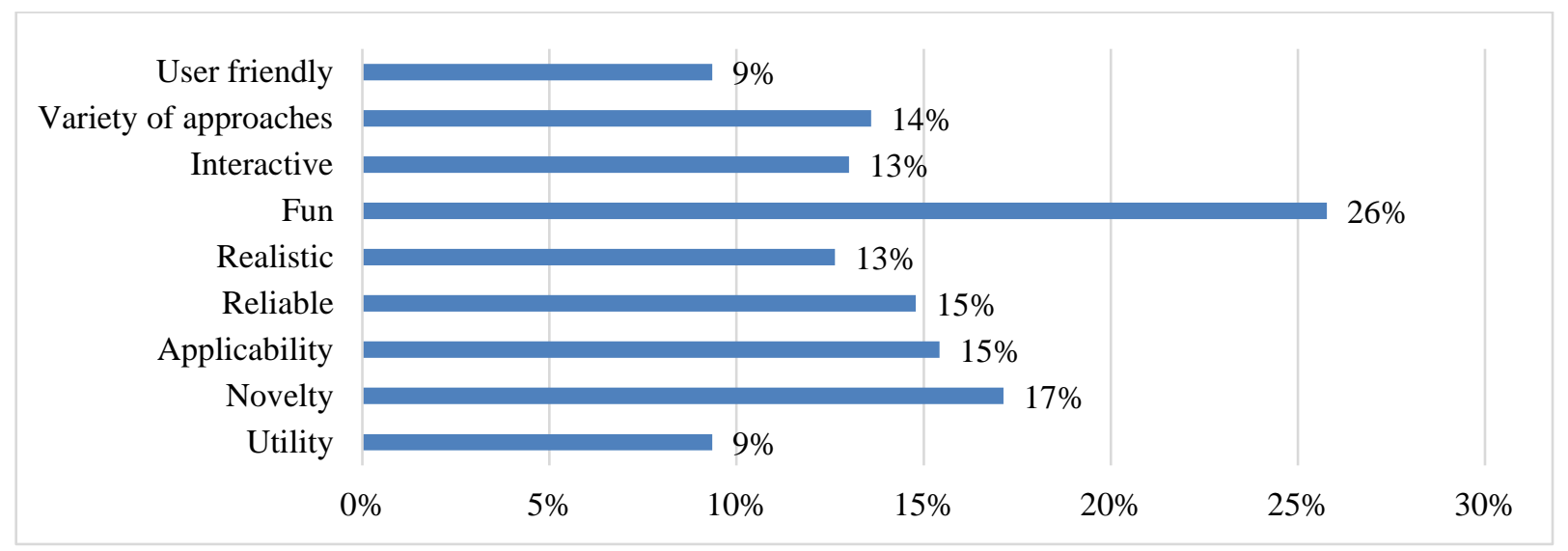

Figure 13. Evaluation of the education material (coefficient of variation)

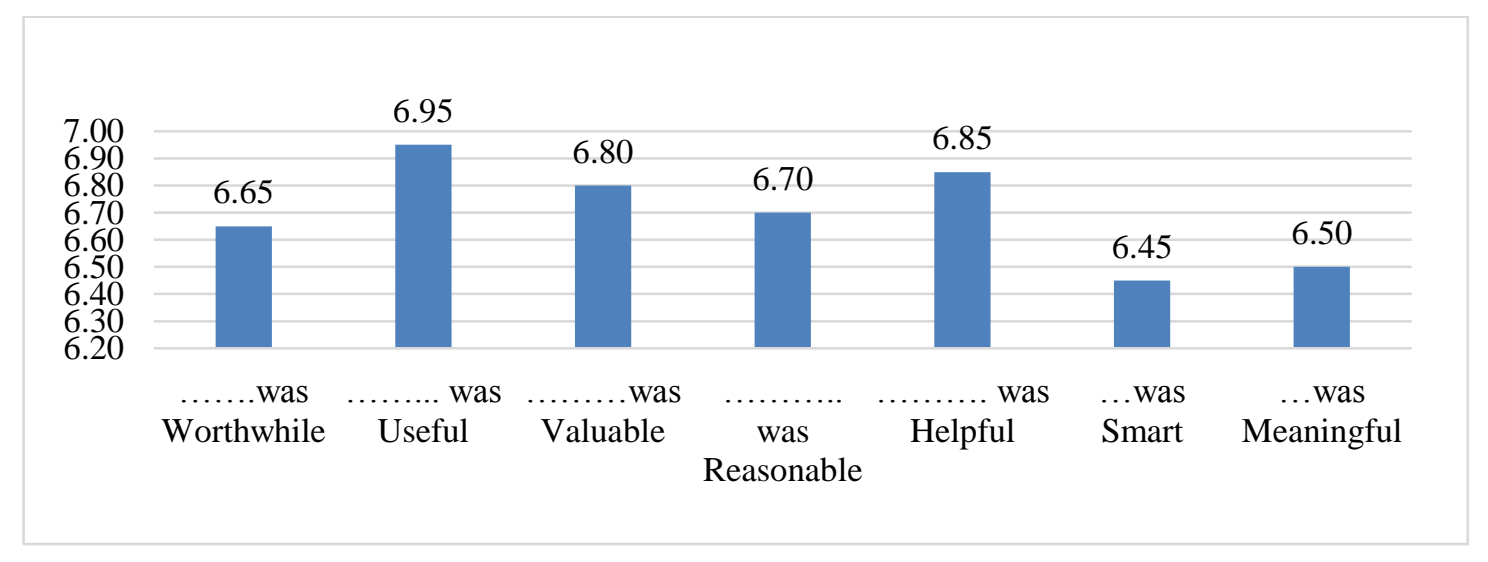

Figure 14. Students' opinions about the course characteristics

\section{Conclusion}

Designed for 28 hours, the course has achieved its objectives by training students in the field of ethics and integrity in sport. Using an interdisciplinary approach, in which sports concepts are supplemented by terms from sociology, anthropology or philosophy, the course helped students to approach ethical issues from multiple perspectives and offered them the opportunity to become acquainted, to recognize and compare the ethics challenges encountered in their activity. The results showed significant increases in the level of specialised knowledge, the skills of identifying and reporting irregularities in sport, but also the learners' susceptibility to act effectively when faced with challenging situations.

The results confirm the research hypothesis that the design and implementation of an ethics and integrity course in sport, with this duration, content, methods and means, can contribute to the development of professional competences. According to the results provided by the above data and based on the observations made by those who delivered this course, the variety of topics and the multitude of case studies created the circumstances to maximise the practicality of the course. Therefore, this course has overcome the weakness of being "boring", as frequently mentioned in ethics studies.

Analysing the three categories of influence exerted on the students by the course of Ethics and integrity in sport, we noticed that, in direct relation with the number of hours and interaction provided by the participation of ANAD specialists, the students felt that they had more knowledge concerning doping compared to the other topics 
covered. However, at the level of action-related skills and predisposition to engage in actions to unmask the consumption of prohibited substances, we have found that the course participants self-assess at a lower level than in the other topic areas. This observation leads to new directions of investigation, given that although the field of doping is regulated by law, students may feel vulnerable when facing the possible consequences of the attitude against the consumption of prohibited substances.

On the other hand, the direct interaction with specialists in the field of anti-doping education (representatives of ANAD) has led to a significant increase in the level of knowledge, compared to other areas of sport ethics. As a result, we believe that the interaction with specialists representing the institutions or organizations active in the fight for the promotion of clean sport is beneficial. The presence of such moral actors or of athletes and coaches who violated the ethical norms and have become aware of this increases the level of empathy and involvement of those participating in the course, leading to a proactive attitude.

\section{Acknowledgment}

The paper was carried out within the Erasmus Plus Sport project "Development of a Course to Teach Coaches Sport Integrity" (2017-3344/ 001-001), coordinated by the Aristotle University of Thessaloniki (Greece).

\section{Authors' Contributions}

All authors contributed equally to this study and should be considered s main authors.

\section{References}

Bertolami, C. N. (2004). Why our ethics curricula don't work. Journal of Dental Education, 68(4), 414-425. Retrieved from https://pdfs.semanticscholar.org/1f1a/3f74b67e39484a267defd51adc1a436ad213.pdf

Bredemeier, B. J., \& Shields, D. L. (1986). Moral growth among athletes and non-athletes: A comparative analysis. The Journal of Genetic Psychology, 147(1), 7-18. https://doi.org/10.1080/00221325.1986.9914475

Duckett, L. J., \& Ryden, M. B. (1994). Education for ethical nursing practice. In J. R. Rest \& D. Narvaez (Eds.), Moral development in the professions: Psychology and applied ethics (pp. 51-70). Hillsdale, NJ: Lawrence Erlbaum Associates, Inc.

Cushion, C. J., Armour, K. M., \& Jones, R. L. (2003). Coach education and continuing professional development: Experience and learning to coach. Quest, 55(3), 215-230. https://doi.org/10.1080/00336297.2003.10491800

Cruz-Cruz, J. A., Curbelo, A. M., \& Frey, W. J. (2010). Doing ethics across the curriculum: The EAC toolkit. Teaching Ethics, 10(2), 47-69. DOI: 10.5840/tej201010211

Dușa, A. (2014). Elemente de analiză comparativă [Elements of comparative analysis]. București: Tritonic. DOI: 10.13140/RG.2.1.3787.2488

Hardman, A., Jones, C., \& Jones, R. (2010). Sports coaching, virtue ethics and emulation. Physical Education \& Sport Pedagogy, 15(4), 345-359. https://doi.org/10.1080/17408980903535784

Hughes, J. C., \& Gallant, T. B. (2016). Infusing ethics and ethical decision making into the curriculum. In T. Bretag (Ed.), Handbook of academic integrity (pp. 1055-1073). Springer. DOI: 10.1007/978-981-287-098$8 \_12$

Narvaez, D. (2010). The emotional foundations of high moral intelligence. New Directions for Child and Adolescent Development, 129, 77-94. https://doi.org/10.1002/cd.276

Mackenzie, B. (2001). Code of Ethics and Conduct for sports coaches. Retrieved from https://www.brianmac.co.uk/ethics.htm

National Youth Sports Coaches Association. (2015). Coaches' Code of Ethics. Retrieved from https://nays.org/cmscontent/file/coe.pdf

Patton, M. Q. (2002). Qualitative research \& evaluation methods. Thousand Oaks, Calif.: Sage.

Wishloff, J. (2005). Teaching ethics: A classroom model. Journal of Business Ethics Education, 2(1), 71-96. DOI: $10.5840 /$ jbee 2005217 